\title{
Porosity and hydric behavior of typical calcite microfabrics in stalagmites
}

\author{
M.B. Muñoz-García a,b,*, P. López-Arce ${ }^{\text {b }}$, M.E. Fernández-Valle ${ }^{\text {c }}$, J. Martín-Chivelet ${ }^{\text {a,b }}$, R. Fort ${ }^{\text {b }}$ \\ a Dto. Estratigrafia, Fac. CC. Geologicas, Universidad Complutense de Madrid, 28040, Madrid, Spain \\ Instituto de Geociencias (CSIC-UCM), C/ José Antonio Nováis 2, 28040, Madrid, Spain \\ ${ }^{\complement}$ Centro de Resonancia Magnética Nuclear (Instituto Pluridisciplinar), Universidad Complutense de Madrid (UCM), 28040, Madrid, Spain
}

\section{Keywords:}

Speleothems

Diagenesis

Porosity

Hydric properties

Paleoclimate

\begin{abstract}
A B S T R A C T
Petrophysical techniques commonly used for material characterization are applied for the first time to speleothem samples to investigate the porosity and hydric behavior of calcite stalagmites used in paleoclimatology. These techniques allow the determination of the stalagmites' potential to undergo diagenetic transformations when substantial changes in drip waters occur in the cave environment. The petrophysical techniques include water absorption under vacuum and by capillarity, nuclear magnetic resonance, environmental scanning electron microscopy, and mercury intrusion porosimetry. The studied samples comprise five common calcite microfabrics, which have markedly different porosities and hydric behaviors and, as a consequence, different sensibilities to diagenetic processes related to the influx of water. The experiments show that stalagmites can behave as complex, small-scale hydrological systems and that the circulation of water through them by complex nets of interconnected pores might be common. As the circulation of water favors diagenetic transformations that involve geochemical and isotopic changes, the characterization of flow patterns is key for outlining areas that are susceptible to such modifications, which is critical to paleoclimatic studies that are based on speleothems because geochemical and stable isotopic data are used as paleoenvironmental proxies and absolute ages are obtained by using radioactive isotope ratios. These potential modifications also have obvious implications for studies based on fluid inclusions in speleothems.

The integrated methodology, which uses primarily non-destructive techniques, shows a high potential for characterization of any type of speleothem and other continental carbonates such as tufas or sinters.
\end{abstract}

\section{Introduction}

Speleothems are widely used in climate change studies. They show a great potential for use in the reconstruction of highresolution paleoclimatic series due to the integration of multi-proxy analysis, the characterization of their internal stratigraphy, and absolute radiometric dating (i.e., U-series). Using this approach, many types of geochemical data (e.g., elemental geochemistry, stable isotopes, and radioactive isotopes) are used and interpreted under the

Abbreviations: AR, anisotropy ratio; C, capillarity coefficient; ESEM, environmental scanning electron microscopy; K, permeability; MIP, mercury intrusion porosimetry; MRI, magnetic resonance imaging; NDTs, non-destructive techniques; NMR, nuclear magnetic resonance; $\mathrm{Pc}$, capillary porosity; PLOM, polarized light optical microscopy; Pm, total open porosity obtained through mercury intrusion porosimetry; PSD, pore size distribution; Pv, open porosity obtained under vacuum; Sc, capillary saturation; Sv, saturation under vacuum; T1, water proton spin-lattice relaxation time in nuclear magnetic resonance; $\mathrm{T} 2$, spin-spin relaxation time in nuclear magnetic resonance.

* Corresponding author at: Dpto. Estratigrafía, Fac. CC. Geológicas, Universidad Complutense de Madrid, 28040, Madrid, Spain. Tel.: + 3491394 4796; fax: + 3491 3944798.

E-mail addresses: mbmunoz@geo.ucm.es (M.B. Muñoz-García), plopezar@geo.ucm.es (P. López-Arce), evalle@pluri.ucm.es (M.E. Fernández-Valle), j.m.chivelet@geo.ucm.es (J. Martín-Chivelet), rafort@geo.ucm.es (R. Fort). basic assumption that speleothems behave essentially as closed geochemical systems.

However, the results of previous petrographical studies suggest that we should be cautious with this assumption. Speleothems often undergo diagenetic processes, such as corrosion and dissolution, micritization, neomorphism (inversion), and recrystallization (e.g., Frisia, 1996; Railsback et al., 1997, 2002; McDermott et al., 1999; Martín-García et al., 2009, 2011). These processes can modify speleothem geochemistry and isotopic ratios and, thus, have critical implications for the interpretations of environmental proxies and radiometric age-dating (e.g., Whitehead et al., 1999; Borsato et al., 2003; Muñoz-García et al., 2007).

Diagenetic alterations occurring in stalagmites are commonly related to changes in the cave environment and in the hydrochemistry of drip waters (e.g., Frappier, 2008). Eventually, these changes can induce the cessation of carbonate precipitation, and a new interaction between drip waters and the carbonate minerals previously deposited can develop. This interaction geochemically alters the surface of the speleothem, and the resulting diagenetic features may be preserved as "altered" stratigraphic intervals if carbonate deposition resumes after a period of no deposition (e.g., Railsback et al., 2011). In some situations, the speleothem surface is permeable enough to allow water percolation, or the waters are corrosive enough to 
generate new percolation paths through the dissolution of existing carbonate. Then, the water enters the speleothem, promoting diagenetic transformations as it flows downwards via a network of connected pores (e.g., Frisia et al., 2000, 2002; Borsato et al., 2003).

This suggests that the distribution of diagenetic processes within speleothems may be controlled strongly by primary porosity and the existence of internal heterogeneities, which determine the favorable pathways for secondary porosity development, water percolation, and water-speleothem interaction. These petrophysical properties should be a function mainly of speleothem microfabrics and internal microstratigraphy.
In this important task of recognizing and interpreting diagenetic patterns in speleothems, it is surprising how little attention has been given to their petrophysical characterization. Petrophysical non-destructive techniques (NDT) commonly used in other research fields (such as material characterization, historical building preservation, or geoarcheology) can be easily applied to speleothems, offering new methods to apply to the study of these rocks. This work is the first attempt of the application of such an approach to speleothems, and it should be of great benefit to future research.

In the context described above, this paper investigates the porosity and hydric behavior of the speleothems that are commonly used

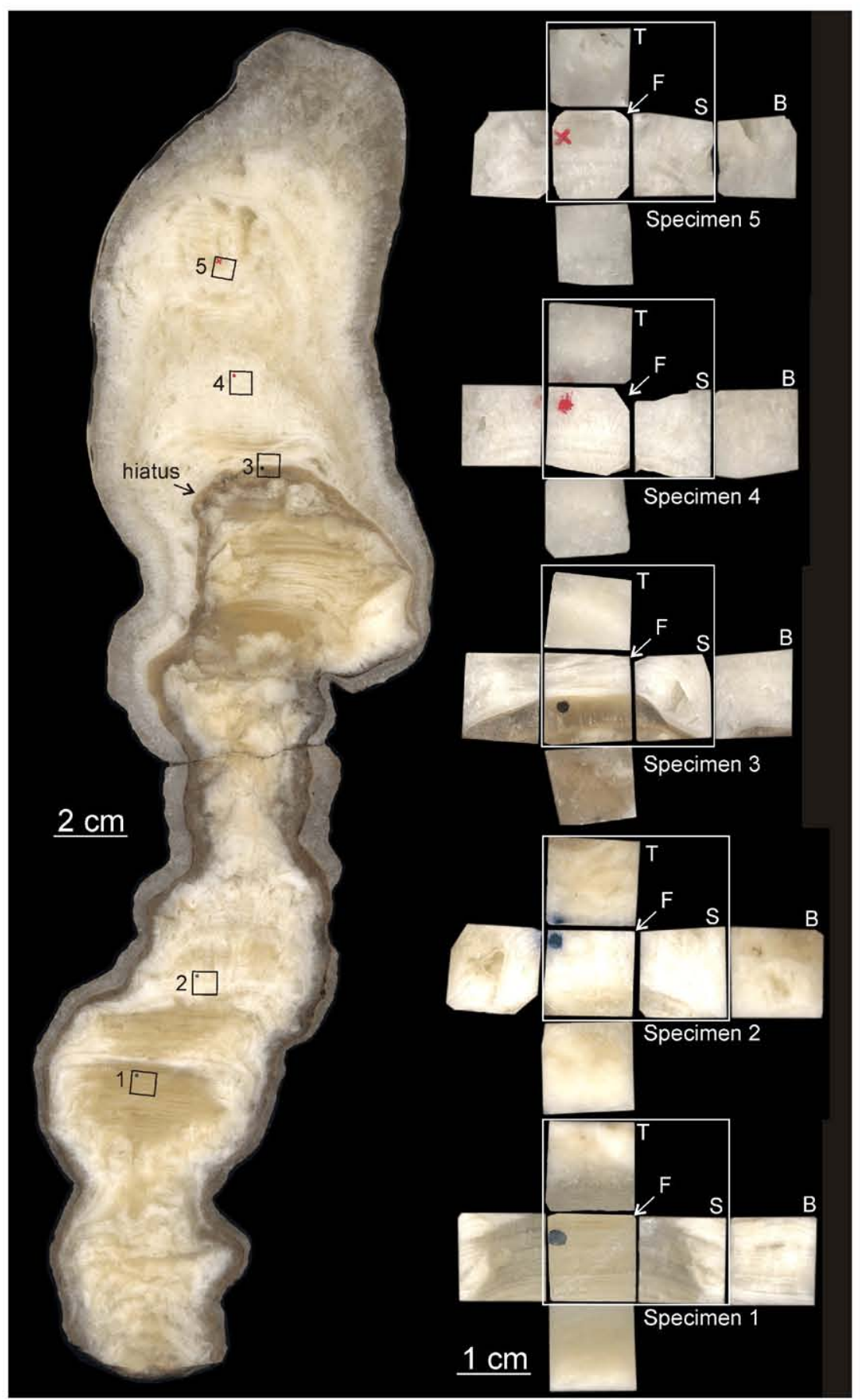

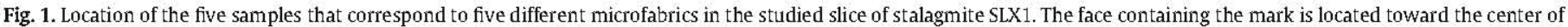

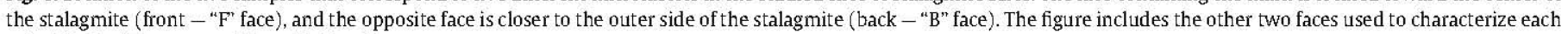
microfabrics ( $\mathrm{T}=$ top and $\mathrm{S}=$ side faces $)$. 
in paleoclimate studies, i.e., calcite stalagmites. These stalagmites, despite their homogeneous mineralogical composition, exhibit a wide variety of microfabrics that depend on the factors affecting their formation (e.g., Frisia and Borsato, 2010). For this study, five different microfabrics, all commonly found in calcite stalagmites, have been investigated using NDTs that include water absorption under vacuum conditions and under atmospheric pressure by capillarity, nuclear magnetic resonance relaxometry and imaging (NMR-MRI), and environmental scanning electron microscopy (ESEM). The results obtained using the NDTs have been compared with those obtained by polarized light optical microscopy (PLOM) and mercury intrusion porosimetry (MIP).

The aim of this research is thus to investigate the porosity and hydric behavior of different microfabrics in calcite stalagmites, to determine their potential to be diagenetically modified, and to discuss their capacity to remain behaving as closed geochemical systems when substantial changes in drip waters occur. The paper demonstrates the potential of applying petrophysical techniques to the study of speleothems. The integrated methodology introduced herein can be applied to any type of speleothem, independently of its mineralogy or stratigraphy, and has great potential to be used for the characterization of other continental carbonate deposits, such as tufas and sinters, with which speleothems share many characteristics.

\section{Material}

The samples used in this research are from a calcite stalagmite collected in Cueva Mayor during a paleoclimate research project. Cueva Mayor is one of the main caves of the Atapuerca karstic system (Burgos Province, Northern Spain). The stalagmite grew in Galería del Silex, a $250 \mathrm{~m}$ long gallery developed in gently dipping Cretaceous limestones. The sampling site is located at $\sim 1050$ masl. and $12-30 \mathrm{~m}$ below the topographic surface (Martín-Chivelet et al., 2006; Ortega, 2009). The climate has a continental influence, with cold winters and hot, dry summers. The mean inter-annual temperature in the area is $\sim 10.8^{\circ} \mathrm{C}$, and the annual rainfall averages $630 \mathrm{~mm}(1990-2002$ interval, Atapuerca meteorological station, Agencia Estatal de Meteorología, $\mathrm{W} 3^{\circ} 30^{\prime} 27^{\prime \prime} \mathrm{N} 42^{\circ} 22^{\prime} 35^{\prime \prime}, 966$ masl). Above the cave, a poor calcareous lithosol exists, and the vegetation is adapted to cold winters and dry summers. The sampling site has no air currents, the relative humidity exceeds $99 \%$, and the air temperature is nearly constant, averaging $10.60{ }^{\circ} \mathrm{C}$ with seasonal changes in the range of $0.02{ }^{\circ} \mathrm{C}$. The stalagmite, labeled SLX1, was slightly moved from its drip point in 1990 during pioneer speleological explorations and latterly collected in 2001. It is $35 \mathrm{~cm}$ long and has a cylindrical shape with an average diameter of $7-8 \mathrm{~cm}$ in the axial part. It is composed of typical laminated calcite microfabrics (sensu Frisia et al., 2000) and preserves a good paleoenvironmental record for the late Holocene (Martín-Chivelet et al., 2011).

The longitudinal slice used in this study is located between the growth axis and the outer part of the stalagmite. The polished section (Fig. 1) shows a very typical distribution of textures. The axial part is completely composed of different types of laminated calcite. The lower part of the section is dominated by translucent calcite with inclusion-rich annual layers and milky calcite with poorly defined lamination. In the middle of the section, a growth hiatus is well outlined by a change in the color and texture of the calcite (Fig. 1). Under the optical microscope, the hiatal surface shows no corrosion features of previously formed calcite. According to U-series age dating of the calcite immediately above and below the hiatus, the growth gap spans a time interval of $\sim 0.3 \mathrm{kyr}$ (Martin-Chivelet et al., 2011). Above the hiatus, the dominant microfabrics are white and milky and show large millimeter-scale pores. The calcite near the surface of the stalagmite is translucent and shows clear evidence of recrystallization; therefore, it will not be used in this study.

For this study, five areas were chosen from this longitudinal slice of the stalagmite (Fig. 1). The main criteria for their selection were the obvious differences in the porosity and lamination features that were observable under a microscope. A sample consisting of a rock cube of $\sim 1 \mathrm{~cm}^{3}$ was retrieved from each site using a diamond saw and then labeled with a number from 1 (the oldest) to 5 (the youngest), according to their relative stratigraphic positions. Some features of each sample (macroscopic appearance, visible lamination, fabric, some characteristics of fluid inclusions, and growth rates) are reported in Table 1.

Sample 1 was chosen from a very finely laminated part of the stalagmite (Figs. 1, 2.1 and 3.1a). Most of the sample ( $~ 85 \%$ in volume) consists on couplets composed of alternating translucent and dark layers of calcite that result from a high concentration of fluid inclusions (Fig. 3.1b). The entire cube is composed of columnar calcite (sensu Kendall and Broughton, 1978; Frisia and Borsato, 2010). For details, see Table 1.

Sample 2 corresponds to a very typical texture in the outer parts of this stalagmite (Fig. 1). It is completely composed of milky laminated dendritic calcite (Fig. 2.2) with the growth layers characterized by a higher concentration of fluid inclusions and pores (Fig. 3.2a and b). In the case of the studied speleothem, the laminated fabrics corresponding to samples 1 and 2 are usually lateral and contemporary equivalents; these are the columnar fabric in the center of the stalagmite and the dendritic fabric that is located toward the outer side of the stalagmite.

Sample 3 was selected to characterize the hydric behavior of a specific layer (the major hiatus) of the stalagmite (Figs. 2.3 and 3.3a). Approximately $45 \%$ of this sample is composed of clean, translucent, and compact calcite similar to the microfabric of sample 1 below the hiatus (Fig. 3.3a b). The calcite crystals located just above the hiatus are very rich in fluid inclusions (Fig. $3.3 \mathrm{c}$ and d). Despite the occurrence of different fabrics, the whole sample is composed of elongated columnar crystals (Frisia and Borsato, 2010) that continued to grow across the hiatus (Fig. 2.3).

Sample 4 was selected from a roughly laminated area of columnar calcite with large voids (Figs. 1, 2.4). The lamination is defined by a thick $(\sim 0.5-1 \mathrm{~mm})$ alternation of layers of non-porous translucent calcite and cloudy layers of calcite. These layers contain millimetersized rounded pores, solid and all-gas fluid inclusions (Fig. 3.4).

Table 1

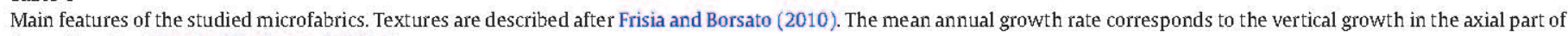
the stalagmite (Martín-Chivelet et al., 2011).

\begin{tabular}{|c|c|c|c|c|}
\hline Sample & Macroscopic appearance & Visible lamination & Texture & Mean annual growth rate $(\mu \mathrm{m} / \mathrm{yr})$ \\
\hline 1 & Translucent & Regular and annual & Elongated columnar or microcrystalline & $310-360$ \\
\hline 2 & Milky opaque, porous & Blurred & Open dendritic & 310 \\
\hline \multirow[t]{4}{*}{3} & Translucent (below the hiatus) & Fine and regular & Elongated columnar & 120 \\
\hline & Dark opaque (hiatus) & Yes & & - \\
\hline & Milky opaque, porous (above the hiatus) & Blurred & & 210 \\
\hline & Translucent (above the hiatus) & Yes & & \\
\hline 4 & Translucent to milky opaque & Blurred & Elongated columnar & $>400($ even 800 to 1700$)$ \\
\hline 5 & Milky opaque. Large pores & No & Elongated columnar or microcrystalline & 400 \\
\hline
\end{tabular}




\section{Parallel polars}
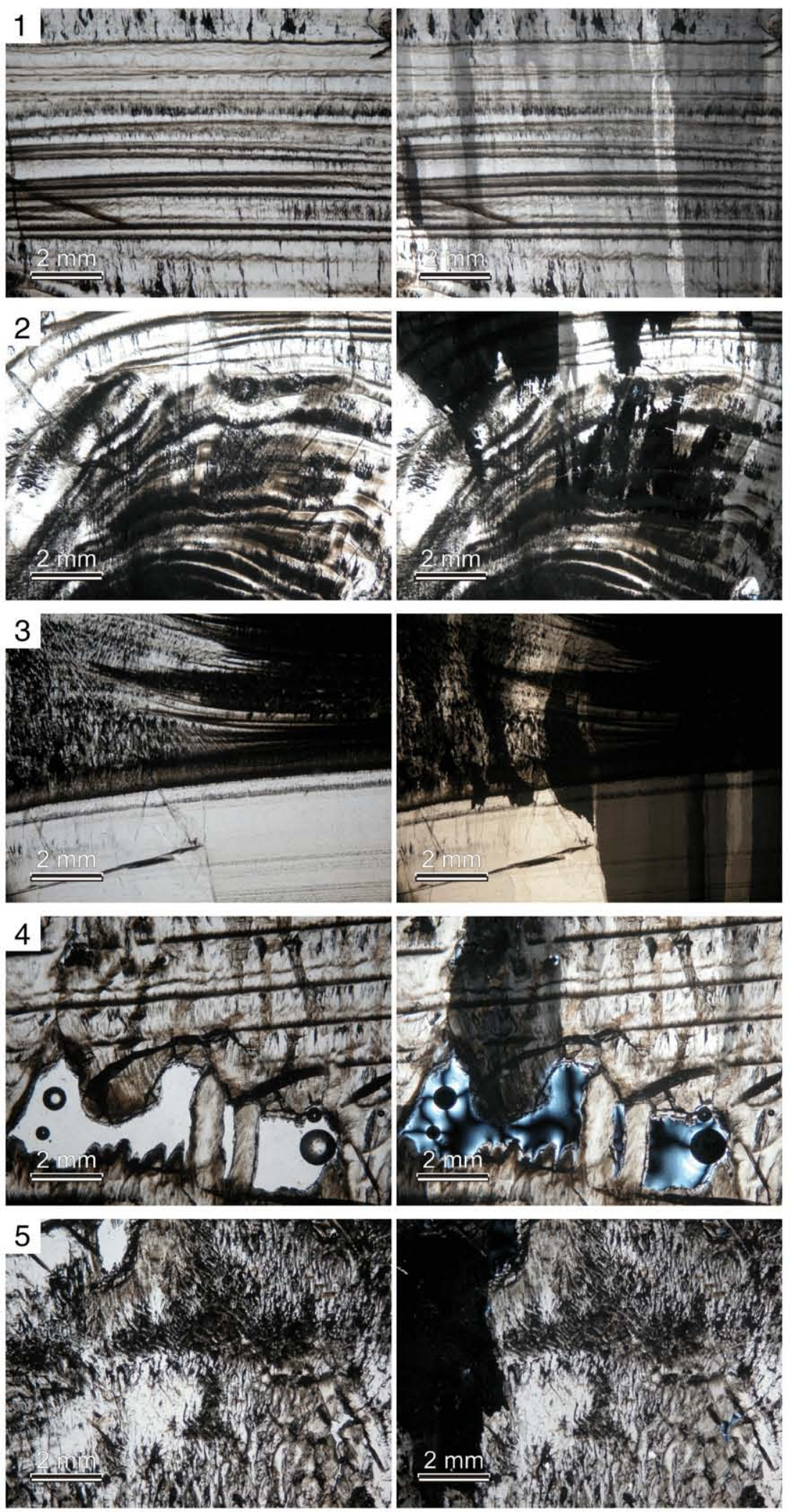

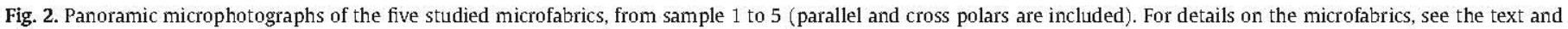
Table 1.

Sample 5 is characterized by the occurrence of large and long pores, most of them having a vertical orientation, associated with centimeter-sized pores (Fig. 1). The structure of the macroscopic growth layers is lost in some parts of the sample (Figs. 2.5 and 3.5). The sample is also composed of elongated columnar calcite (Frisia and Borsato, 2010). See Table 1 for more details. 

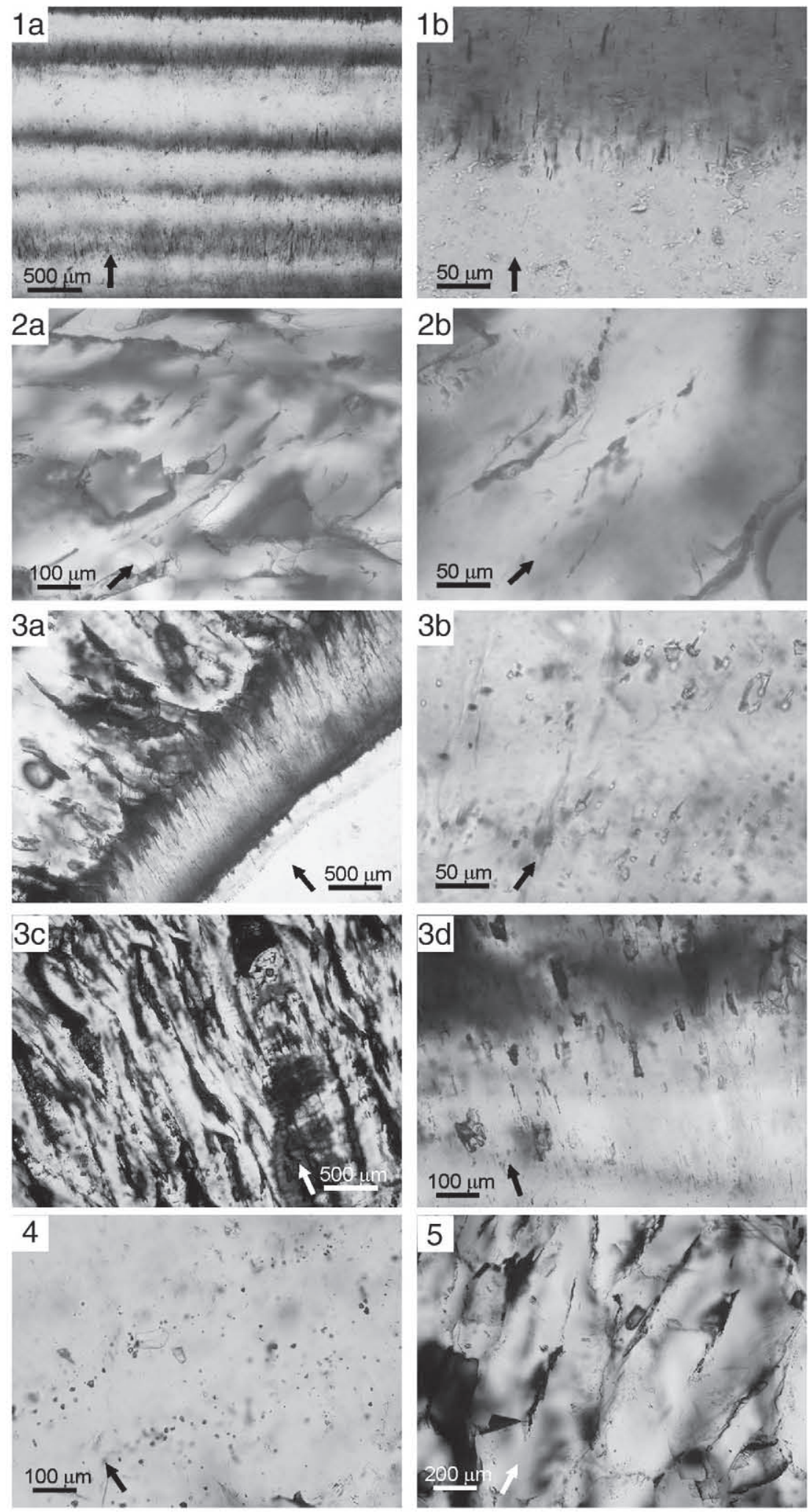

Fig. 3. Magnified view of the five studied microfabrics under a polarized light optical microscope (parallel polars). The arrows indicate the direction of crystal growth. 1a and b) Annual growth layers in sample 1. The opaque part of the couplet is formed by the accumulation of elongated fluid inclusions. 2) Typical aspect of pores and fluid inclusions in the dark (a) and translucent (b) layers of sample 2.3) Different microfabrics included in sample 3: (3a) The hiatus, formed by two parallel layers, divides the sample between translucent calcite (3b) and milky opaque calcite (3c and 3d).4) Solid inclusions and all-gas fluid inclusions aligned in growth layers in sample 4. 5) Relation between pores and fluid inclusions in sample 5 .

In all cases, the face with the number of the sample is located toward the center of the stalagmite (" $\mathrm{F}$ " side), and the opposite face is closer to the outer side of the stalagmite ("B" side). The top ("T") and one of the sides ("S"), both perpendicular to the growth axis, were also used in the characterization analyses and are indicated in Fig. 1. 

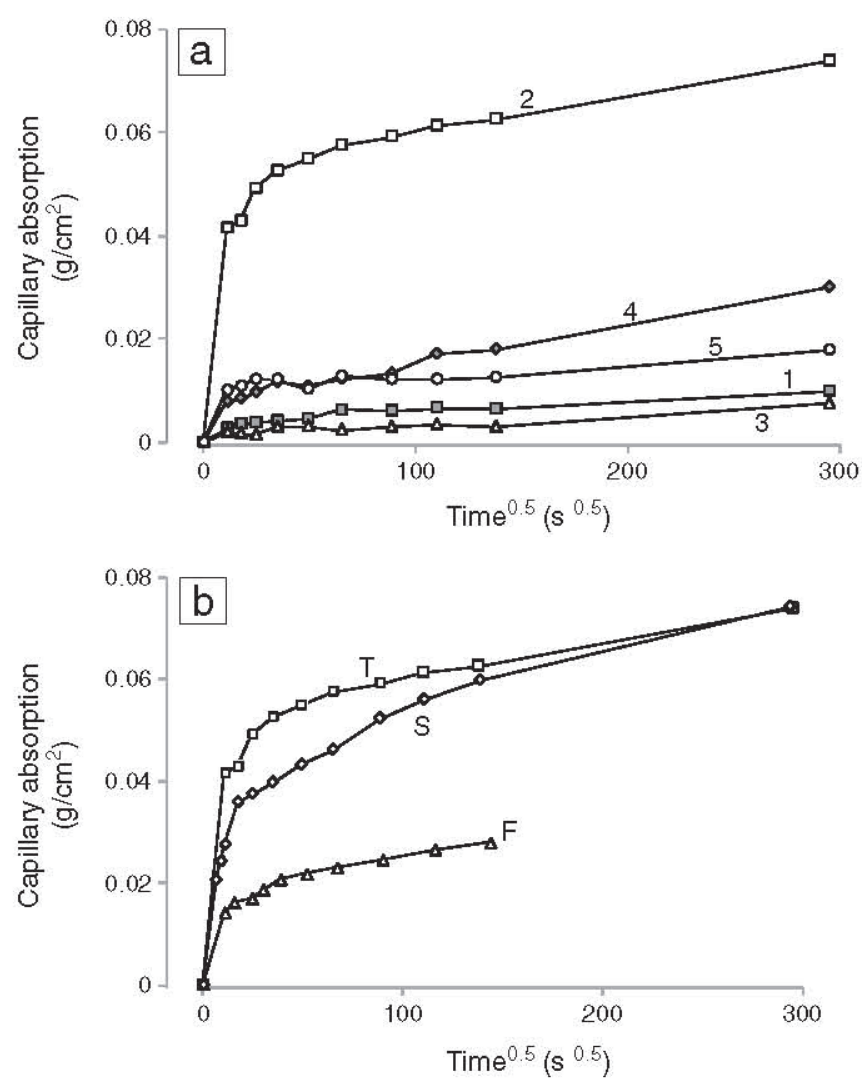

Fig. 4. Results of the capillarity tests. a) Capillary absorption curves of the top face of the five samples. b) Capillary absorption curves of three faces $(T=$ top; $F=$ front; $\mathrm{S}=$ side) of sample 2 .

\section{Methods}

To determine the porosity and hydric behavior of the stalagmite samples, several analytical techniques have been applied as follows. Between each analysis, the samples were dried in a desiccator with silica gel ( $2-3 \%$ relative humidity) until each sample reached a constant weight.

\subsection{Water absorption by capillarity}

Capillarity was performed to study the capillary porosity and the hydric behavior through the sample using two methods: the Italian standard test NORMAL 11/85, 1985 and a continuous data-recording ACUASOR. The balance is linked to a computer that automatically records the weight gain in the tested sample at specified intervals of $(1 / f) s^{1 / 2}(f=2$ in the current study). It allows automatic monitoring

of the water uptake by the sample when its lower surface is in contact with the water reservoir.

A typical capillary absorption curve can be divided into two parts: the first part defines the capillary absorption, and the second one defines the capillary saturation (Fig. 4). The slope of the curve obtained during capillary absorption is the capillary absorption coefficient, $\mathrm{C}\left(\mathrm{g} / \mathrm{m}^{2} \mathrm{~s}^{0.5}\right)$, the rate of water transport. Higher $\mathrm{C}$ values are related to a larger mean capillary pore radius and higher connected porosity. Additionally, the coefficient $\mathrm{C}$ is related to the square root of the permeability, $\mathrm{C} \propto \sqrt{\mathrm{k}}$ (Zimmerman and Bodvarsson, 1991; Benavente et al., 2007). Thus, using correlations between the capillary absorption coefficient and water permeability in porous stones (Benavente et al., 2007), the permeability $k$ may be estimated as follows: $\sqrt{ } \mathrm{k}(\mathrm{mD})$ $\sim 3 \mathrm{C}\left(\mathrm{kg} / \mathrm{m}^{2} \mathrm{~h}^{0.5}\right)$. On the other hand, the capillary porosity (Pc) can also be calculated according to the method of Benavente et al. (2002), as indicated by Eq. (1),

$\left(W_{H 2 O} / d_{H 2 O}\right) / V_{\text {sample }}$

where $W_{H 2 O}$ is the total quantity of water absorbed until the capillary-saturation, $\rho_{H z O}$ is the water density (ca. $1 \mathrm{~kg} / \mathrm{l}$ ) and $V_{\text {sample }}$ is the volume of the sample.

The capillarity coefficient $(\mathrm{C})$, permeability $(\mathrm{K})$, capillary saturation $(\mathrm{Sc})$, and capillary porosity (PC) of each sample were estimated in the three spatial directions within the cubic samples (T, F and S; Fig. 1). The coefficient $C$ was also used to calculate an anisotropy ratio $(A R)$ for each sample. The $A R$ was defined as $C_{F}: C_{T}: C_{S}$, with $C_{F}$ standardized to equal 10 to allow comparison among the samples.

\subsection{Water absorption under vacuum}

Saturation (Sv) and open porosity (Pv) were obtained from the samples, as described in Spanish and European standard UNE-EN, 1936: 2007, using natural stone test methods. Once the samples reached a constant weight in the desiccator, they were introduced into a vacuum chamber at $2 \mathrm{kPa}$ for $2 \mathrm{~h}$. Then, after a slow immersion in water, they were left submerged in this chamber at atmospheric pressure for $24 \mathrm{~h}$.

Saturation (Sv) and open porosity (Pv) under vacuum were calculated as indicated by Eqs. (2) and (3),

$$
\begin{aligned}
& \operatorname{Sv}(\%)=\frac{W s-W d}{W d} \cdot 100 \\
& \operatorname{Pv}(\%)=\frac{W s-W d}{W s-W h} \cdot 100
\end{aligned}
$$

where $W s$ is the weight of the sample saturated with water for $24 \mathrm{~h}$, $W d$ is the weight of the dry sample, and Wh is the weight of the sample under water for $24 \mathrm{~h}$.

The test was performed just before the NMR analyses to fully saturate the samples with water.

Table 2

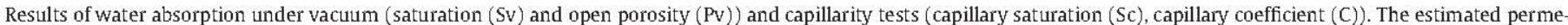

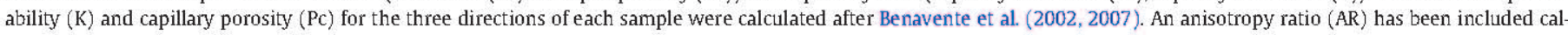

\begin{tabular}{|c|c|c|c|c|c|c|c|c|c|c|c|c|c|c|c|c|}
\hline \multirow{2}{*}{\multicolumn{2}{|c|}{$\frac{\text { Parameter }}{\text { Sample face }}$}} & \multirow{2}{*}{$\frac{\mathrm{Sv}(\%)}{\mathrm{All}}$} & \multirow{2}{*}{$\frac{\text { Pv (\%) }}{\text { All }}$} & \multicolumn{3}{|c|}{$\mathrm{Sc}(\%)$} & \multicolumn{3}{|c|}{$\mathrm{C}\left(\mathrm{g} / \mathrm{m}^{2} \mathrm{~s}^{0.5}\right)$} & \multicolumn{3}{|l|}{$\mathrm{K}(\mathrm{mD})$} & \multicolumn{3}{|c|}{$\operatorname{Pc}(\%)$} & \multirow{2}{*}{$\frac{A R}{F: T: S}$} \\
\hline & & & & $\mathrm{F}$ & $\mathrm{T}$ & $\mathrm{S}$ & $\mathrm{F}$ & $\mathrm{T}$ & S & $\mathrm{F}$ & $\mathrm{T}$ & $\mathrm{S}$ & $\mathrm{F}$ & $\mathrm{T}$ & S & \\
\hline \multirow[t]{5}{*}{ Sample } & 1 & 2.8 & 7.2 & 0.13 & 0.38 & 0.38 & $0.4 \pm 0.0$ & $2.1 \pm 0.2$ & $2.2 \pm 0.2$ & 0.005 & 0.14 & 0.16 & 0.34 & 1.05 & 1.14 & $10: 53: 55$ \\
\hline & 2 & 5.6 & 13.1 & 1.14 & 2.99 & 2.71 & $10.9 \pm 1.9$ & $14.7 \pm 1.2$ & $34.8 \pm 1.3$ & 3.85 & 7.00 & 39.24 & 2.84 & 7.50 & 7.55 & $10: 13: 32$ \\
\hline & 3 & 2.1 & 5.3 & 0.91 & 0.23 & 0.63 & $13.9 \pm 0.6$ & $0.7 \pm 0.2$ & $41.4 \pm 2.3$ & 6.26 & 0.016 & 55.53 & 3.09 & 0.98 & 2.89 & $10: 0.5: 30$ \\
\hline & 4 & 3.8 & 9.3 & 1.06 & 0.91 & 1.05 & $24.1 \pm 0.9$ & $25.1 \pm 0.6$ & $25.0 \pm 0.6$ & 18.82 & 20.41 & 20.25 & 4.29 & 4.40 & 5.84 & $10: 10: 10$ \\
\hline & 5 & 2.8 & 7.1 & 0.41 & 0.56 & 0.41 & $13.2 \pm 2.1$ & $19.6 \pm 2.7$ & $15.6 \pm 2.0$ & 5.65 & 12.45 & 7.88 & 1.69 & 2.53 & 1.99 & $10: 15: 12$ \\
\hline
\end{tabular}
culated as $\mathrm{C}_{\mathrm{F}}: \mathrm{C}_{\mathrm{T}}: \mathrm{C}_{\mathrm{S}}$ (being $\mathrm{C}_{\mathrm{F}}=10$ ). 

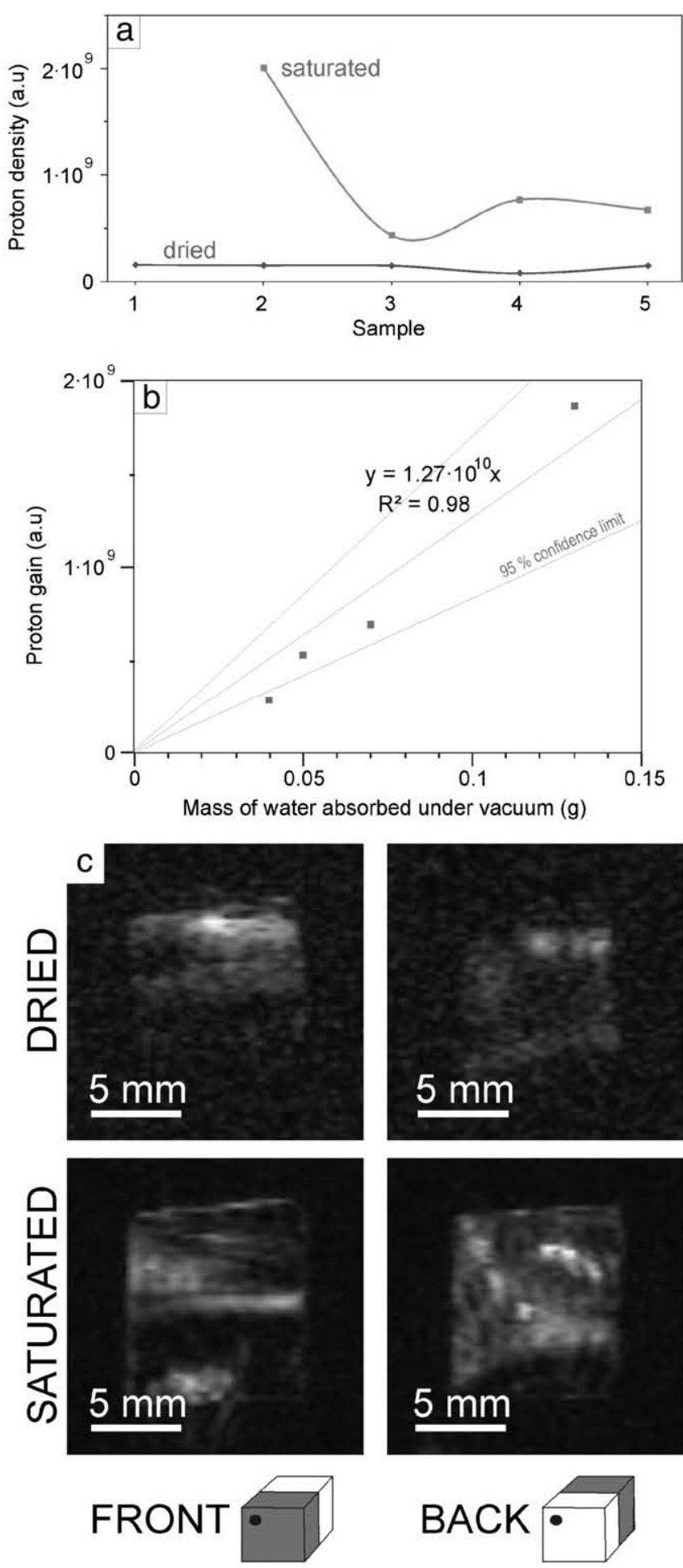

Fig. 5. Results of NMR-MRI analyses. a) Proton density signal of dried and saturatedwith-water samples (sample 1- the saturated sample could not be analyzed properly). b) Relation between mass of water absorbed by each sample after the saturation under vacuum test versus the related increase in proton density. The function shown on the graph can be deduced. c) Magnetic resonance images obtained for each slice (front and back halves) of dried and saturated sample 3 .

\subsection{Nuclear magnetic resonance: relaxometry and imaging (MRI)}

NMR was used to observe and to quantify the location and distribution of water inside the pores of the samples. The same relaxometry experiments were performed on dried samples and on samples fully saturated with water. To avoid water evaporation during NMR

experiments, the saturated samples were covered with parafilm. For the dried samples, the water proton spin-lattice (T1) and spin-spin (T2) relaxation data allowed the evaluation of the effect induced by the presence of fluid inclusions trapped inside or between the calcite crystals. The second analyses performed on the saturated samples allowed the study of their pore structure (open and closed porosity).

All NMR experiments were performed using a BIOSPEC BMT 47/40 spectrometer (Bruker, Ettlingen, Germany), operating a 4.7 T. A $3.5 \mathrm{~cm}$ Bruker-designed volume radio frequency coil was used for transmission and reception. For longitudinal relaxation time (T1) measurements, a standard inversion-recovery spin-echo sequence was used. A total of 50 inversion times (TI) were acquired. The TI for the dried samples was $20 \mathrm{~ms}$, and it was $100 \mathrm{~ms}$ for the saturated ones. The transverse relaxation time (T2) was measured using a CarrPurcell-Meiboom-Gill (CPMG) sequence. The echo time (TE) was $1 \mathrm{~ms}$ for the dried samples and $2 \mathrm{~ms}$ for the saturated samples. A total of 75 echoes were acquired.

These measurements were transferred to a $\mathrm{PC}$ and processed to obtain the quasicontinuous relaxation time distribution curves using the UpenWin 1.02 program (University of Bologna, Italy).

For all dried and saturated samples, spin-echo images were acquired to observe the spatial distribution of the water. The parameters for these images were as follows: repetition time (TR) $=5000 \mathrm{~ms}$, $\mathrm{TE}=3 \mathrm{~ms}$, field of view (FOV) $=3 \mathrm{~cm}$, slice thickness (SLTH) $=5 \mathrm{~mm}$ and number of averages $(\mathrm{NA})=2$. The acquired matrix size was $128 \times 64$. These data were zero-filled to obtain a reconstructed matrix size of $128 \times 128$.

For saturated samples, a series of images was acquired to calculate localized T2. The series consist of 20 images acquired with the same $\mathrm{TR}, 3140 \mathrm{~ms}$, and different TE values. The TE values varied from $5.2 \mathrm{~ms}$ to $138.2 \mathrm{~ms}$. The FOV was $23 \mathrm{~cm}$. For each sample, four $2.5 \mathrm{~mm}$ slices were acquired. The matrix size for acquisition and reconstruction was $128 \times 128$. These data were processed using the Image Sequence Analysis (ISA) tool of the ParaVision 3.01 software (Bruker, Ettlingen, Germany).

\subsection{Environmental scanning electron microscopy (ESEM)}

Environmental scanning electron microscopy was also used to analyze the samples non-destructively because it eliminates the need for additional rock polishing and metal coating. The morphology of the crystals and the shape and size of the pores were studied using an Inspect FEI ESEM with an Oxford Instrument Analytical 7509 energy dispersive X-ray spectroscope (EDS) for compositional, semiquantitative analyses. UTHSCSA Image Tool V3 software was used to perform pore size measurements on the ESEM images.

\subsection{Polarized light optical microscopy}

The samples were also studied under polarized light optical microscopy (PLOM) to characterize their mineralogy and texture. Petrographic examination was performed using a Nikon Eclipse E400 POL microscope on double-polished, uncovered petrographic sections, approximately $\sim 500 \mu \mathrm{m}$ thick. The PLOM analysis was especially useful to describe the fluid inclusions and to study the relation among pores, crystals, and growth layers.

\subsection{Mercury intrusion porosimetry}

Mercury intrusion porosimetry (MIP) was applied to assess sample pore structure, i.e., total open porosity (Pm), tortuousness, and pore size distribution (PSD). Readings were taken in pore diameters of 0.005 to $400 \mu \mathrm{m}$ under measurement conditions ranging from close-to-atmospheric pressure up to 60,000 psia (228 MPa) with a Micromeritics Autopore IV 9500 MIP. 


\section{Results}

\subsection{Water absorption by capillarity and under vacuum}

Table 2 displays the results obtained after the water absorption under vacuum test -saturation (Sv) and open porosity (Pv)-, and after the capillarity test, including $\mathrm{C}$ coefficient, the capillary saturation value ( $\mathrm{Sc}$ ), the estimated value of the permeability $(\mathrm{K})$, the capillary porosity (Pc), and the anisotropy ratio (AR) in the three studied faces ( $F, T$ and $S$ ) of each sample. The main characteristics of all the capillary curves obtained, with the exception of sample 2, are (1) a low rate of water absorption ( $\mathrm{C}$; gentle slopes in Fig. $4 \mathrm{a}$ ) and (2) a small amount of water absorbed by capillary rising $(\mathrm{Sc}$ ) before capillary saturation (Table 2 and Fig. 4a).

Despite this general similarity, the five samples show different Sc and $C$ values, and their behaviors differ depending on which face of the cube was tested (Fig. $4 \mathrm{~b}$ and Table 2 ). The $\mathrm{C}$ coefficient ranges between the value obtained from the front face (F) of sample $1(0.4 \pm$ $\left.0.0 \mathrm{~g} / \mathrm{m}^{2} \mathrm{~s}^{0.5}\right)$ and that from the side face $(\mathrm{S})$ of sample $3(41.4 \pm$ $\left.2.3 \mathrm{~g} / \mathrm{m}^{2} \mathrm{~s}^{0.5}\right)$. This latter, relatively high $\mathrm{C}$ coefficient is associated with a low Sc value for the same face $(0.63 \%)$. At the same time, sample 1 and sample 3 show the lowest $\mathrm{Sc}$ and $\mathrm{C}$ values obtained for the top faces (T) (Fig. 4a). Accounting for the three spatial directions for $F$, $\mathrm{T}$ and $\mathrm{S}$ faces, sample 1 yields the lowest $\mathrm{C}$ and $\mathrm{Sc}$ values $(<2.2 \pm$ $0.2 \mathrm{~g} / \mathrm{m}^{2} \mathrm{~s}^{0.5}$ and $<0.38 \%$, respectively for the three faces), and sample 4 yields the highest $\left(\mathrm{C}>24.1 \pm 0.9 \mathrm{~g} / \mathrm{m}^{2} \mathrm{~s}^{0.5}\right.$, and $\left.\mathrm{Sc}>0.91 \%\right)$. However, sample 2 yields the highest Sc values $(>1.14 \%)$ in the three directions (Fig. $4 \mathrm{~b}$ and Table 2), despite its $\mathrm{C}$ coefficient, which falls in the middle of the range $\left(>10.9 \pm 1.9 \mathrm{~g} / \mathrm{m}^{2} \mathrm{~s}^{0.5}\right)$.

The capillary porosity values (Pc in Table 2 ) vary between $0.34 \%$ (sample 1, F) and 7.55\% (sample 2, S). However, the most outstanding result is the extremely low permeability $(\mathrm{K}<0.16 \mathrm{mD})$ of sample 1 , for all the tested faces and for sample 3 across the hiatus (vertical direction - face $\mathrm{T} ; \mathrm{K}=0.016 \mathrm{mD}$ ). Except for this case, the front face (F), the one located toward the inner part of the stalagmite, always displays the lowest $\mathrm{C}$ values in all the samples.

Regarding the anisotropy ratio, samples 4 and 5 are the most isotropic (AR of 10:10:10 and 10:15:12, respectively), while the other three samples show very marked anisotropy.

The results of the water absorption under vacuum test are also displayed in Table 2 . Samples 2 and 3 represent extreme and opposite behaviors related to saturation (Sv) and total open porosity (Pv). Sample 3 (the hiatus sample) yields the lowest Pv (5.3\%) and Sv (2.1\%) values, while sample 2 yields the highest $\mathrm{Pv}(13.1 \%)$ and $\mathrm{Sv}$ (5.6\%) values. Sample 4 also shows relatively high $\mathrm{Pv}$ and $\mathrm{Sv}$ values (9.3\% and $3.8 \%$, respectively). The other two samples, although formed by very different textures (Figs. 1, 2.4 and 2.5), display very similar values that are in the middle of the range (Pv between 7.1 and $7.2 \%$ and $\mathrm{Sv}=2.8 \%$ for both samples).

\subsection{Nuclear magnetic resonance: MRI and relaxometry}

The samples were analyzed under MRI before and after the water absorption under vacuum test (i.e., dried and saturated, respectively, in Fig. 5 and Table 3). The proton density signal of the dried samples is related to the amount of original water retained in their fluid inclusions, whereas the proton density signal of the saturated samples includes both the water from their fluid inclusions and the water absorbed during the vacuum test. The proton density values are quite low and broadly similar in all of the dried samples, with the exception of sample 4, which shows a slightly lower value (Fig. 5a). An empiric function has been estimated to relate the amount of water present in a sample to the proton density detected by the NMR instrument (Fig. Sb). The difference between the results obtained with saturated and dried samples (Table 3) allowed us to estimate that the proton density values increase by $1.27 \cdot 10^{10}$ with each gram of water absorbed under vacuum $\left(R^{2}=0.98\right)$. Then, we can assume that the water trapped inside the calcite crystals in its natural environment should cause a similar effect. Therefore, it is possible to estimate the amount of water trapped in the fluid inclusions (\% weight in Table 3). In the five studied samples, this estimated amount varies between 0.34 (sample 4) and $0.68 \%$ (sample 5). This estimation is in agreement with the signal intensity of the MRI (sample 3 is shown as an example in Fig. 5c). Additionally, these images allow us to recognize the internal distribution of trapped water and open porosity. In sample 3, most of the fluid inclusions appear to be preserved in the front slice of the sample (Fig. 5c, dried). When the sample is saturated, the internal structure of its front slice becomes clearly visible because of the concentration of water, mainly along the growth layers and the hiatus (Fig. 5c, saturated). The MRI images of all of the saturated samples are presented in Fig. 6.

All the samples reveal remarkably similar relaxation curves (T1 and T2) when dried (Fig. 7a and c). The water trapped in the fluid inclusions provokes T1 relaxation times between 100 and $1000 \mathrm{~ms}$ and T2 relaxation times between 1 and $100 \mathrm{~ms}$, in all cases. However, when the samples are saturated, many differences appear: T1 curves are shifted toward higher values, especially in samples 2, 3 and 4, which show a narrow spike between 1000 and $3000 \mathrm{~ms}$ (Fig. 7b). The similarity in the $\mathrm{T} 2$ curves of the dried samples (Fig. 7c) is also lost when the samples are soaked (Fig. 7d). T2 values become higher (up to $800 \mathrm{~ms}$ ), and the distribution curves become bimodal in the case of samples 1 and 3 . Sample 5 shows a unimodal curve with a wide plateau at shorter relaxation times. These changes in the relaxation times are related to the pore sizes of fluid inclusions and to the connected porosity of the samples, as discussed in the following section.

\subsection{Optical light and environmental scanning electron microscopy}

Polarized optical light microscopy was used to measure and describe the fluid inclusions in each microfabric. The primary or

Table 3

General description and main features of the characteristic fluid inclusions of each microfabric under the petrographic microscope.

\begin{tabular}{|c|c|c|c|c|c|}
\hline \multirow[t]{2}{*}{ Sample } & \multirow[t]{2}{*}{ Macroscopic appearance } & \multicolumn{4}{|l|}{ Fluid inclusions } \\
\hline & & Modal size $(\mu \mathrm{m})$ & Liquid:vapor & Origin & Description \\
\hline 1 & Translucent & $3-4$ & All liquid to $10: 90$ & Primary & Aligned in growth layers \\
\hline 2 & Milky opaque, porous & $5-30$ & $70: 30$ & Primary & Many are broken \\
\hline \multirow[t]{4}{*}{3} & Translucent (below the hiatus) & $8-12$ & All liquid to $10: 90$ & Primary & More biphasic than sample 1 \\
\hline & Dark opaque (hiatus) & $25-100$ & All liquid to $70: 30$ & Primary and secondary & Necking-down? Broken \\
\hline & Milky opaque, porous (above the hiatus) & $100-200$ & $?$ & Primary & Broken \\
\hline & Translucent (above the hiatus) & $2-30$ & All liquid to $90: 10$ & Primary & Aligned in growth layers \\
\hline 4 & Translucent to milky opaque & 10 & All gas to $50: 50$ & Primary & Aligned in growth layers \\
\hline \multirow[t]{2}{*}{5} & Milky opaque. Large pores & $10-25$ & All liquid to $80: 20$ & Primary & Along $c$ axis \\
\hline & & 2 & $?$ & Secondary & Perpendicular to pores \\
\hline
\end{tabular}



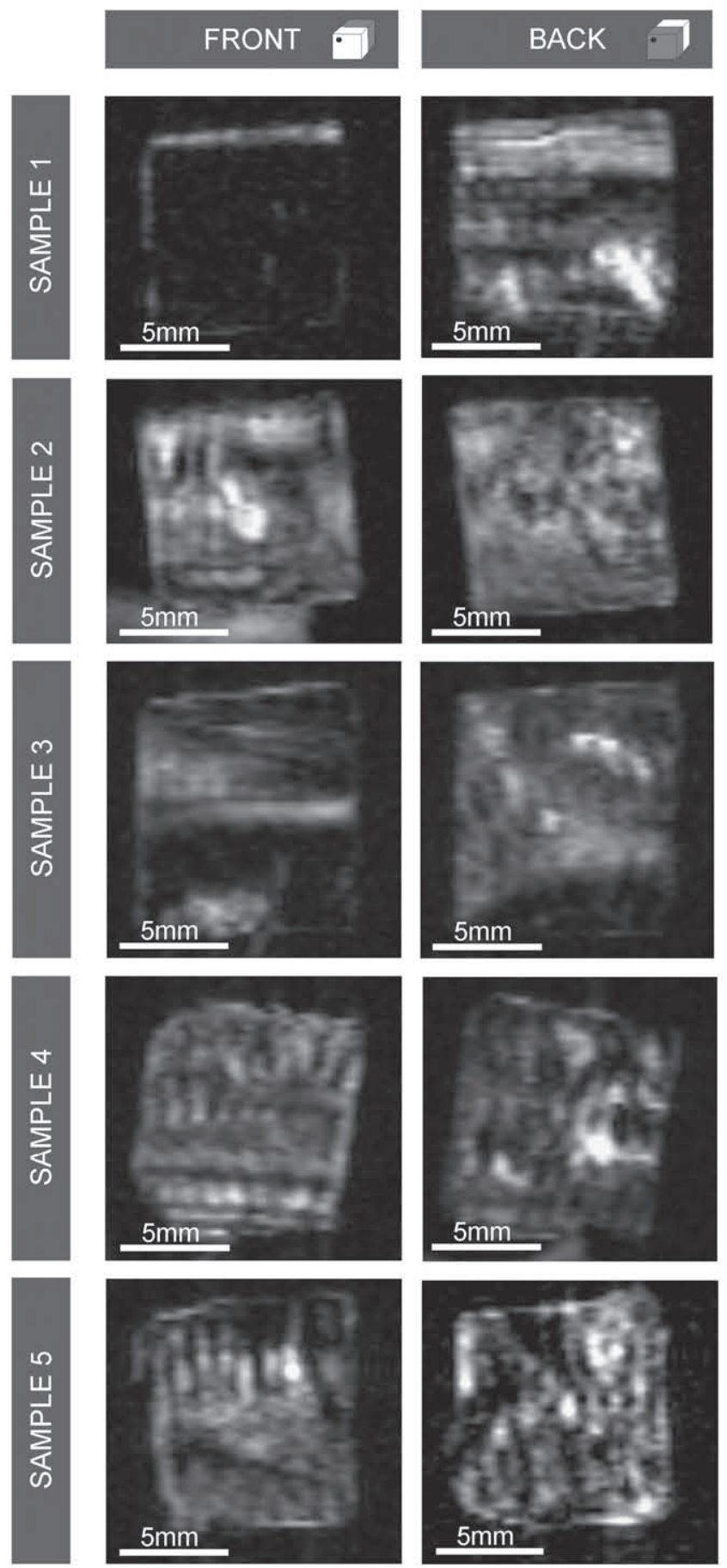

Fig. 6. MRI images obtained in the stalagmite cubic samples after water absorption saturation under vacuum. a,b) Front and back parts, respectively, of microfabrics 1 ; c,d) Front and back parts of microfabrics 2; e,f) Front and back parts of microfabrics $3 ; g$,h) Front and back parts of microfabrics 4; i,j) Front and back parts, respectively, of microfabrics 5 .

secondary origin of the fluid inclusions is deduced according to the method of Goldstein (1993). The results are shown in Table 3. Most of the microfabrics preserve primary fluid inclusions. They are usually elongated or horn-shape in the growth direction of the calcite crystal and are grouped along growth layers. The liquid:vapor ratio ranges from all-liquid to all-gas. Secondary fluid inclusions were found only in two microfabrics; some inclusions from the hiatus in sample 3 appear to have suffered necking-down processes. Additionally, the distribution of some small inclusions in sample 5 is not related to crystal growth directions but to the orientation of large pores.

The ESEM photographs allowed the study of the shape and size of the pores that were visible in the front $(\mathrm{F})$, top $(\mathrm{T})$ and side $(\mathrm{S})$ faces of each cubic sample (Fig. 8). Fig. 9 shows a plot of the percentage of porosity vs. the diameter of the pores measured on the ESEM images. The pore size measurements show that the diameters of most of the pores in all the samples are concentrated in two groups: the range between 1 and $10 \mu \mathrm{m}$ and from 10 to $100 \mu \mathrm{m}$. Samples 2, 4 and 5 also show some amount of pores with diameters exceeding $100 \mu \mathrm{m}$.

The microscope images (PLOM in Fig. 3 and ESEM in Fig. 8) show that sample 1 has the smallest pore sizes on the three studied faces. Most of the pores are aligned along the growth layers. Very few inter-crystalline elongated pores exist on the $\mathrm{F}$ and $\mathrm{S}$ faces (circa $100 \mu \mathrm{m}$ length and $3 \mu \mathrm{m}$ width). Only on the top face are there areas with cavernous, irregular, and rounded pores. Sample 3 also shows very few pores. They are usually small, elongated or rounded and are aligned along growth layers, especially over the hiatus (Fig. 3.3 and Fig. 8). Some large voids are visible on the side face (S) of the sample. The samples with the largest pores are samples 2 and 5. The top face of sample 2 displays the largest pores (Fig. 8), whose shape is completely dependent on the dendritic texture of the calcite crystals, together with some rounded or elongated medium- and small-sized pores. The most outstanding feature of sample 5 is the occurrence of very large pores, with a marked vertical development and an inhomogeneous distribution on the surfaces (Fig. 3.5 and 8). The growth layers are not recognizable. Finally, sample 4 has also large pores with vertical development. Some of them are rounded, while others have elongated shapes with evidence of corrosion, dissolution or re-precipitation, primarily on the top face. The position and shape of the pores are structurally controlled, and they are more common in the inter-crystalline boundaries and along the growth layers (Figs. 3.4 and 8 ).

\subsection{Mercury intrusion porosimetry}

The total connected porosity (Pm), tortuousness, and pore size distribution (PSD) have been obtained through mercury intrusion porosimetry (MIP) analyses in all of the stalagmite samples (Fig. 9 and Table 2S).

The five samples show relatively similar PSD. Most of the connected pores can be classified into three well-defined groups: between 1 and $4 \mu \mathrm{m}$, between 10 and $40 \mu \mathrm{m}$, and between 100 and $200 \mu \mathrm{m}$. Samples 3, 4 and 5 show very similar, almost unimodal, curves (most of the pore diameters range between 10 and $40 \mu \mathrm{m}$ ) and have similar values of total connected porosity (between 4.6 and $7.8 \%$ ). The PSD curve for sample 2 displays a polymodal curve with the same mode but with higher numbers of pores belonging to the other two groups $(1-4 \mu \mathrm{m}$ and $100-200 \mu \mathrm{m})$. Additionally, this sample yielded the highest value of Pm (10.7\%). Sample 1 displays the lowest Pm (1.6\%) and the most complex polymodal PSD curve. The families of pore size are exactly the same as for the other samples, but the total porosity is equally distributed among all of them. The calculated values of tortuousness are very similar for all the samples, between 4.4 and 6.3 ; the lowest values correspond to sample 1 and the highest to sample 4 .

\section{Discussion}

The NDTs used in this study have proved to be useful in two ways: (1) to test the possible interaction between the speleothems and drip water and (2) to characterize the internal structure of different speleothem microfabrics. The percentage of total open porosity is tested by water absorption under vacuum, NMR in saturated samples, and MIP techniques. The possible paths for water entrance in the sample are revealed mainly through water absorption by capillarity and 

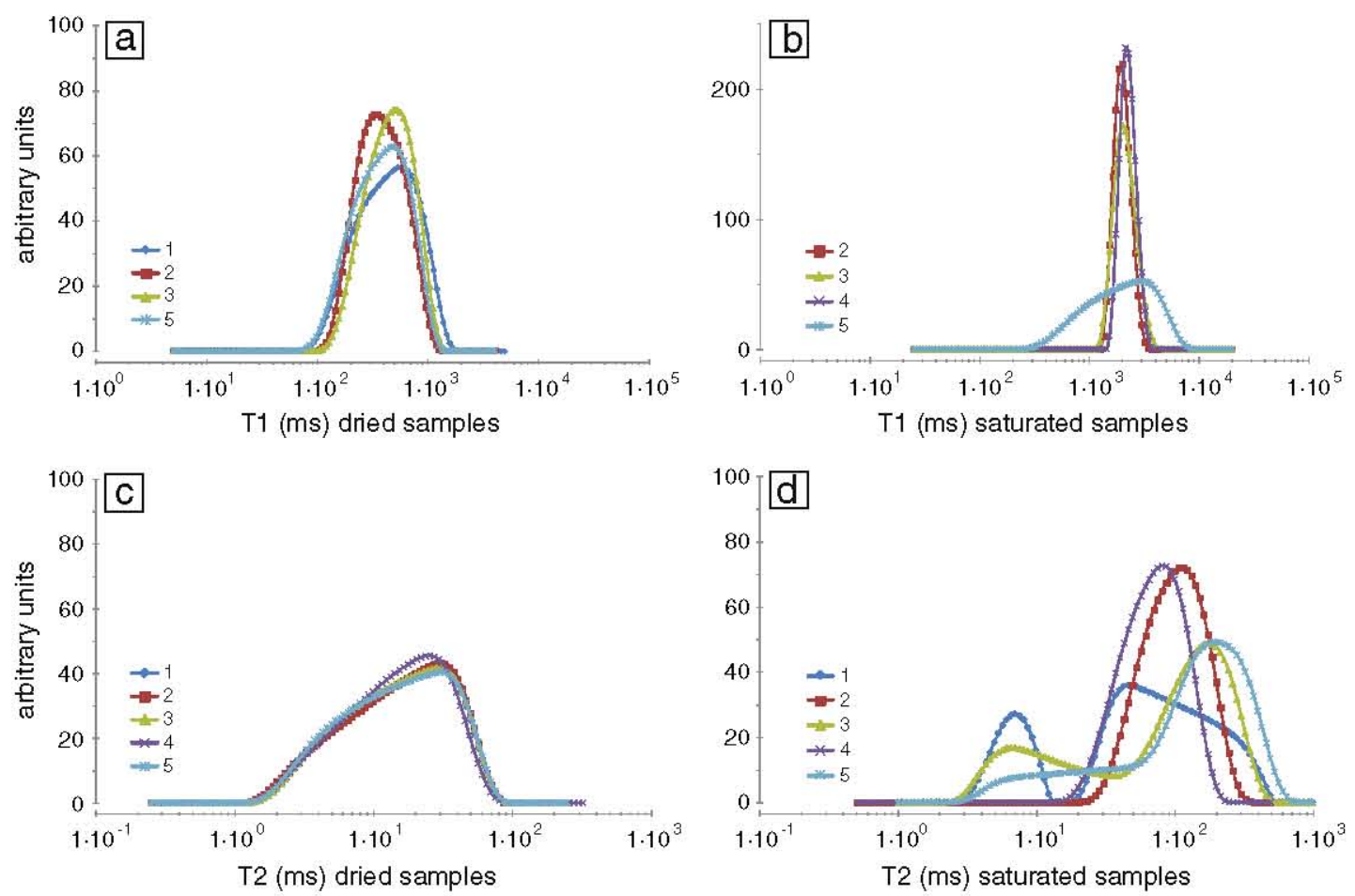

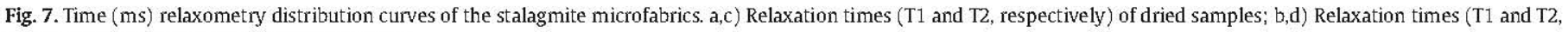
respectively) of samples saturated with water.

ESEM techniques. The 3D distribution of the open porosity and the internal fabric of each microfabrics can be observed in MRI slices (Fig. 6) and quantified by means of relaxometry (Fig. 7). Finally, the NMR-MRI techniques, when applied to dried samples, have shown to be useful in estimating the amount of water trapped in the samples as fluid inclusions, their size, and the 3D distribution (Fig. 5). To confirm the validity of the results obtained through NDTs, these techniques were complemented with PLOM and MIP. Our findings indicate that these characteristics are very different for each of the microfabrics.

\subsection{Open porosity: hydric behavior, type, shape, and pore size distributions}

\subsubsection{Primary microfabrics}

Samples 1 and 2 correspond to very common primary speleothem microfabrics. The microfabric corresponding to sample 1 is often used in paleoclimate studies because it allows the dating of annual growth layers by counting (Baker et al., 1993; Proctor et al., 2000), which can be used in conjunction with other dating methods. The dendritic microfabric of sample 2 is usually associated with unstable and irregular drip rates (Frisia et al., 2000 and Frisia and Borsato, 2010). These growth conditions are very common in the outer parts of some stalagmites. In these cases, microfabric 2 may be the lateral equivalent to microfabric 1. Despite this closeness in space and time, the hydric behavior of both microfabrics is very different. Sample 1 shows extremely low values for hydric movement, while sample 2 is the most active microfabric with respect to hydric kinetics.

The ESEM images (Fig. 8) show the most likely entrance paths for water, which, in sample 1 , are located mainly in the top face (the sponge-like texture toward the back of the image of Fig. 8-1T) and in the side face (the very small pores toward the lower part of the image 8-1S). The open porosity appears to be structurally controlled because the absorbed water concentrates along the growth layers in the back part of the sample, according to the MRI results (Fig. 6). On the other hand, the most effective pores, in terms of capillary flux, in sample 2 appear to be those of the side face, which are the smallest ones, according to the ESEM images (Fig. 8.2). The large pores on the top face appear to be the result of dendritic growth. Although the size is quite outstanding, the connectivity must not be too high, according to the permeability values. The absorbed water concentrates very homogeneously inside the entire sample (Fig. 6), but some large pores are located in the front part, possibly in the space left by the dendritic habit. In contrast to sample 1 , this microfabric is very isotropic. The permeability rises in the side face $(S)$, where the growth layers may behave as preferential paths for water.

Some data on the size and shape of open porosity can also be deduced from the comparison of the saturation under vacuum and the NMR results. According to some authors, even though the "size" determined by relaxation measurements tends to correspond to pore dimensions, whereas MIP results are related to the size of the pore throats (the channels between pores), what both techniques usually have in common is shape of the distributions (Viola et al., 2006). This is very true in the case of the T2 curve of sample 1 , although the relaxation curves are usually more simple and show narrower distributions or a main peak with a plateau, indicating greater microstructural homogeneity than do the MIP curves. However, some differences arise in the case of sample 2 . These differences are most likely the result of a good connection among open pores because a single pore surrounded by other well-connected pores will yield a single peak in the relaxation time distribution (Borgia et al., 2001). Additionally, the dendritic habit of the crystals of sample 2 highly increases the surface-to-volume ratio of the pores. The larger the ratio between the pore volume and its surface area is, the longer the T1 value (Alesiani et al., 2003a, 2003b), which reaches T1 $=3 \mathrm{~s}$ for bulk water. Samples 1 and 2 have significant spectral weight at T1 $=3 \mathrm{~s}$, indicating that they contain a substantial fraction of unconfined fluid when saturated. Therefore, the open porosity is formed by large pores in which relaxation is primarily due to bulk processes (Latour et al., 1995). The amount of bulk water is so great that its effect on relaxometry time masks the smaller pores. The most important characteristics of the hydric behavior of these samples appear to 


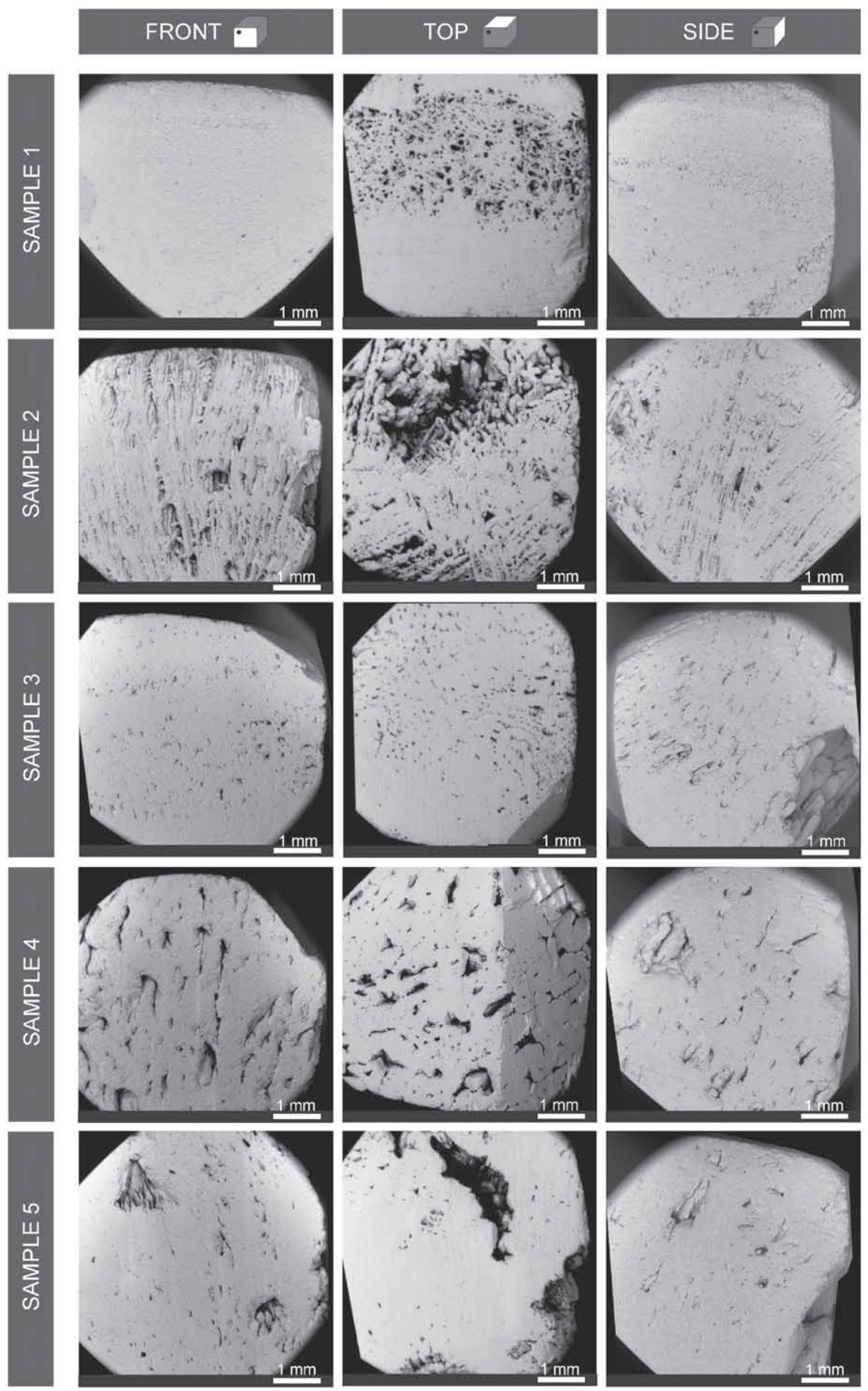

Fig. 8. ESEM images obtained in the three spatial directions ( $F=$ front; $T=$ top; $S=$ side $)$ of the five studied samples.

be related to the primary features of each microfabric: growth lamination and dendritic habit.

\subsection{Diagenetically altered microfabrics}

Samples 4 and 5 correspond to two microfabrics that can appear in the external parts of some speleothems. In this case, both are coeval with higher growth rates in the axial part of the stalagmite (Table 1). They are characterized by millimeter-to-centimeter-sized pores in laminated columnar calcite. Microfacies 4 shows large pores broadly elongated in the directions of growth layers and especially developed in the crystal boundaries (Fig. 5). The large voids of microfacies 5 are accompanied by a loss of growth lamination. Both microfabrics have medium-to-high values for open porosity and saturation under vacuum.

The ESEM images of sample 4 (Fig. 8.4) show elongated pores (up to $2 \mathrm{~mm}$ long in the vertical direction) that can have a rough " $\Pi$ " or " $\Gamma$ " shape in the front face (F) of the sample and are rounded in the top face $(\mathrm{T})$. The vertical component that is distinguishable in the ESEM images also can be observed in the MRI slices. The water absorbed under vacuum concentrates in very large voids in the back part of 

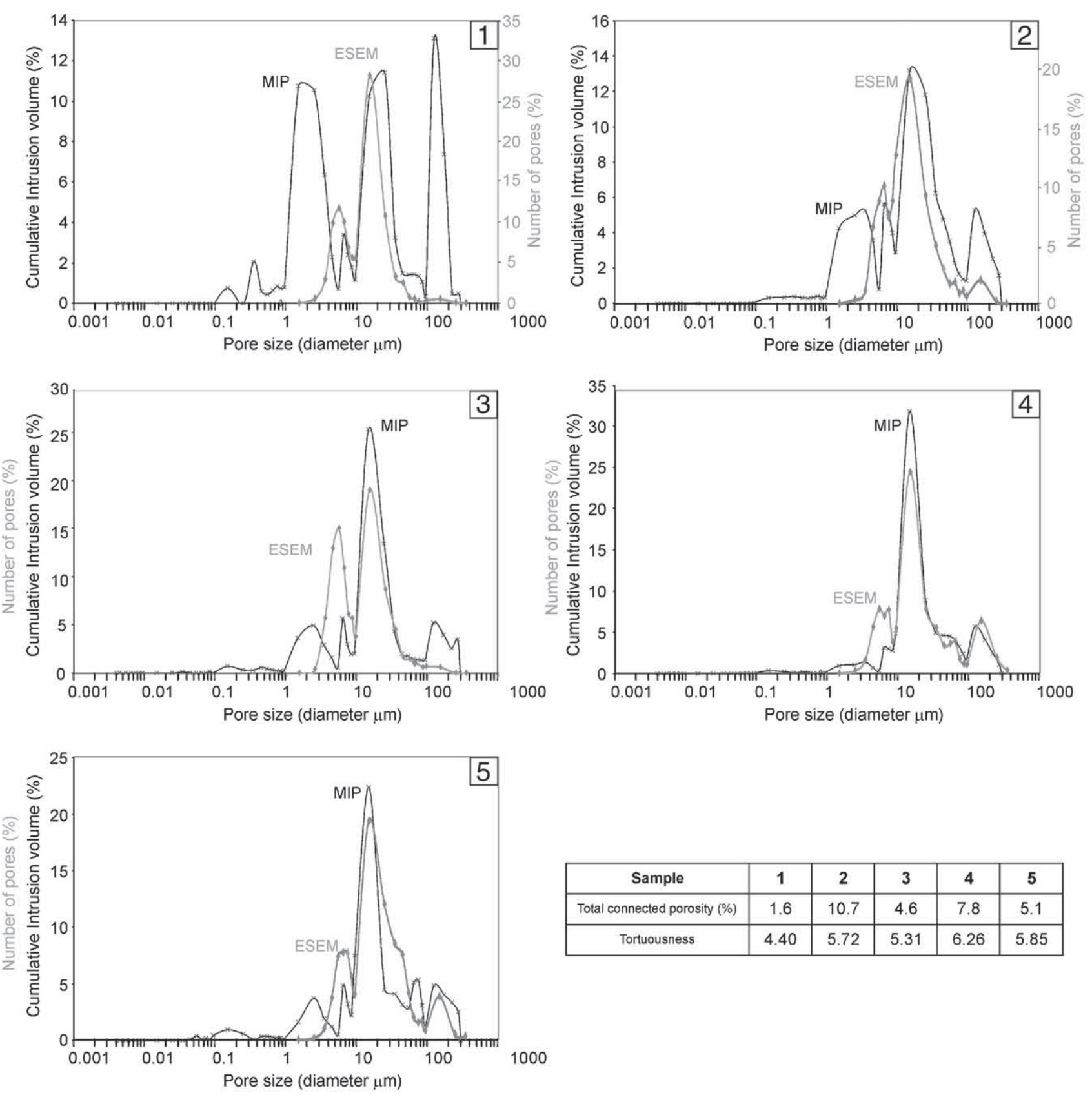

\begin{tabular}{|c|c|c|c|c|c|}
\hline Sample & $\mathbf{1}$ & $\mathbf{2}$ & $\mathbf{3}$ & $\mathbf{4}$ & $\mathbf{5}$ \\
\hline Total connected porosity $(\%)$ & 1.6 & 10.7 & 4.6 & 7.8 & 5.1 \\
\hline Tortuousness & 4.40 & 5.72 & 5.31 & 6.26 & 5.85 \\
\hline
\end{tabular}

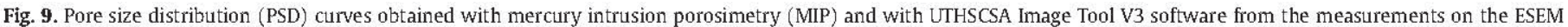
images of the stalagmite samples. The total porosity and tortuousness results obtained with MIP and PSD from both techniques are indicated.

the sample (Fig. 6) or in aligned pores along the growth layers in the front part. In sample 5, the pores on the front and side faces have a " $\lambda$ " shape, with the number of branches increasing downward (Fig. 8.5). The image of the top face shows large sections of these pores (up to $4 \mathrm{~mm}$ long) with a very complex shape. The absorbed water under vacuum concentrates homogeneously inside the front part of the sample (Fig. 6.5). The NMR front slice resembles the vertical features that can be observed on the PLOM images (Figs. 2 and 3). In the back part of the samples, most of the water is absorbed into vertically connected large voids (Fig. 6.5). Additionally, the wider shape of the pore size distribution curve of sample 5 compared to the others is likely due to a greater microstructure inhomogeneity.

Samples 4 and 5 display large pores and marked isotropy. Additionally, both present an enhanced vertical permeability with respect to the primary microfabrics of samples 1 and 2 . Together, these data suggest that the porosity and permeability may have been enhanced by diagenetic alterations in samples 4 and 5 . In sample 4 , however, the microstructure has not been completely erased because it is still easily recognizable in the saturated NMR images (Fig. 6.4). Not all the calcite has been altered in this sample, and the diagenetic alteration has been limited to the enlargement and interconnection of pre-existing pores or fluid inclusions. On the other hand, sample 5 shows some features that are different from the other four samples, such as the PSD, the T1 curves and the preservation of secondary fluid inclusions. These differences, together with the loss of almost all primary structural features observed in the microscope images (PLOM and ESEM), indicate diagenetic alteration. Diagenesis may have been responsible for the enlargement and migration of pores 
by dissolution processes and for the decrease in the pore sizes by calcite re-precipitation and necking-down of some pores, increasing the variability of diameters.

\subsubsection{Hiatus}

Sample 3 was chosen to test a non-corrosive hiatus surface. The conclusions obtained hereafter cannot be compared with those from other samples because this specimen corresponds to the heterogeneous repartition of at least three different microfabrics. Thus, we cannot know what the nature of the hydric behavior will be for all the hiatuses in speleothems, but these results may have the potential to be useful in deducing the behavior of other non-corrosional growth discontinuities involving short-time hiatuses in the stalagmite records ( 200 to 300 years). Hydrical data from sample 3 indicate a lateral preferential porous connection along the hiatus in the concentric direction (side face). Additionally, the hiatus is related to the total disconnection of the vertical pores and the virtual partition of the stalagmite in independent hydric subsystems, even inside the same columnar crystals.

The high anisotropy ratio (10:0.5:30) is not clearly observable in the ESEM images (Fig. 6). It is possible to see very similar small pores along the well-developed growth layers in both the front and top faces, while the side face presents some enlarged pores of millimeter size. This external difference is most likely insufficient to explain the large anisotropy that this sample displays with respect to its hydric properties. The absorbed water concentrates mostly on top of the hiatus in small pores that, horizontally aligned, broadly resemble growth layers (Fig. 6.3). On the other hand, the part of the cube located below the hiatus does not absorb any water. Primary fluid inclusions are preserved in this area, and thus, the lack of open porosity below the hiatus seems to be primary in origin and caused by a slowing growth rate that allowed the complete coalescence of crystallites (as described by Kendall and Broughton, 1978). The calcite located above the hiatus is also formed by elongated columnar fabric, but the hydric behavior is completely different.

\subsection{Closed porosity: fluid inclusions}

Despite the large differences observed in the open porosity of the five studied microfabrics, the results involving closed porosity are very similar. The $\mathrm{T} 1$ and $\mathrm{T} 2$ relaxometry curves are virtually identical for all the dried samples. According to the broad estimation obtained from the saturated relation between MIP and NMR, the range of diameters of fluid inclusions for the five microfabrics could vary between 0.03 and $25 \mu \mathrm{m}$ (the mode would be $\sim 3-7 \mu \mathrm{m}$ ). The PLOM observations revealed intact monophasic and biphasic fluid inclusions from $\sim 3$ to $30 \mu \mathrm{m}$ long with a mode between 5 and $12 \mu \mathrm{m}$ (larger inclusions are usually broken). The ratio of water:air in the biphasic inclusions varies between 95:5 and 10:90. In fact, the lowest values for the estimated diameters based on $\mathrm{T} 2$ data could be related to the effect of the biphasic inclusions. The water film trapped between the calcite and the air bubble in some of the inclusions with a high air: water ratio would yield very small pore diameters.

The estimated water mass trapped in the samples varies between 0.34 and $0.68 \%$, which is in agreement with the calculations made by other authors. Speleothems may contain from 0.11 to $0.93 \%$ of relict drip water in the form of fluid inclusions, according to Harmon et al. (1979), or a somewhat less, up to $0.67 \%$ in arid or semiarid areas (McGarry et al., 2004). However, these values are too high if compared with those reported elsewhere: up to $0.1 \%$ of relict drip water, according to Kendall and Broughton (1978), or between 0.06 and $0.27 \%$ (Dennis et al., 2001).

The fluid inclusions observed in the present study are usually located in the back part of the samples, and for the most part, they are aligned along the growth layers (such as in samples 2, 3 and 4) or in a broadly vertical pattern, such as in samples 1 and 5 . This vertical distribution is very homogeneous in sample 5 , which again suggests a diagenetic alteration but seems to be very inhomogeneous in sample 1 and could be controlled by the primary crystal boundaries.

\subsection{Implications for further paleoclimate studies}

Although it is well known that stalagmites are often very porous and that the presence of large, interconnected pores can be easily detected (by the generation of bubbles in water when submerging the speleothems, for instance), the 3D interconnection of such porosity remains poorly understood. The combination of techniques applied in this work allows us to obtain some important conclusions that are relevant to future studies.

The speleothem system is usually assumed to behave as a closed system. The studied samples, chosen from an inner part of a stalagmite, present higher values for open porosity than expected (from 5.3 to $13.1 \%$ ), though that does not necessarily imply alteration or continuous water flow through them. Borsato et al. (2003) suggest that some speleothems could act as an open system through intercrystalline planes. They point to the fine intercrystalline porosity that might act as a filter, retarding or even immobilizing organic acids that transport allogenic ${ }^{230} \mathrm{Th}$ in undersaturated waters. The intercrystalline planes as interchange paths have also been suggested by Genty et al. (2002), who observed the progressive drying of a $6 \mathrm{~cm}$ long fluid inclusion on a speleothem during the first month after its extraction from the humid paleoenvironment of the cave. On the other hand, they observed several fluid inclusions that did not change at all, generally situated further from the surface that generated by cutting with the saw (Genty et al., 2002). Thus, we strongly suggest completely drying all samples in a desiccator until a constant weight is reached before using them in paleoclimate studies.

In the present study, the water entrance paths were checked by ESEM. They are not only cleavage or intercrystalline planes but also round pores. According to our results, the calcite might be altered around the pores in samples 4 and 5 but possibly not in the inner part of the crystals, away from pores, where the primary textures are still preserved.

The study of the anisotropy through capillary absorption yielded interesting results. Despite the expected variability in the hydric behavior among all of the samples, the front face is always the part of the sample with the lowest permeability. This result is important because this face is usually used for paleoclimate studies.

Perhaps, the most important implication for future paleoclimate studies is the potential to apply NMR-MRI techniques to dried or saturated speleothems. These techniques allow the determination of the location and quantification of the amount of fluid inclusions and open porosity with an NDT. Additionally, the similarity between the T1 and T2 curves when the samples are dried (Fig. 7a and c) and the shifts of the relaxometry curves to longer values after saturation (Fig. 7) suggests that the type of trapped fluid inclusions is similar in all samples and that the observed changes could be due to water absorption by the larger pores. The NMR-MRI techniques could be applied to any paleoclimate study that is based on fluid inclusions. Large fluid inclusions were identified with this technique, and this finding could be important in the future. Genty et al. (2002) found macroscopic fluid inclusions in the polished translucent parts of the stalagmites and measured the $\delta^{18} \mathrm{O}$ and $\delta \mathrm{D}$ of the water. They admitted that these macroscopic inclusions might exist in the opaque white porous parts, but it was not possible to find them due to the milkiness of the sample. In their case, only three out of 15 polished stalagmites revealed macroscopic fluid inclusions because of the presence of bubbles. These authors suggested that macroscopic fluid inclusions could be even more abundant but undetectable to the naked eye if they are completely filled with water (Genty et al., 2002). The possibility of finding and quantifying the amount of fluid inclusions by means of NMR-MRI before cutting or polishing the samples could help in 
estimating the recovery percentage and greatly improve the different methods of isotopic analysis: direct injection from macroscopic fluid inclusions (Genty et al., 2002), thermal decrepitation (Matthews et al., 2000; McGarry et al., 2004), or crushing and heating (Dennis et al., 2001; Fleitmann et al., 2003; Vonhof et al., 2006). Additionally, a petrophysical characterization and a petrographical study of stalagmite microfabrics are essential to assure the contemporaneity of laterally coexisting water and calcite to date the trapping of the inclusion.

Finally, the MIP results indicate some general characteristics that are common to all the studied microfabrics. The pore size distribution is determined by the varying percentages of only three main groups of pore diameters: between 1 and $4 \mu \mathrm{m}$, between 10 and $30 \mu \mathrm{m}$, and from 100 to $300 \mu \mathrm{m}$. Further studies will be necessary to evaluate the potential to extrapolate these groups of diameters to other speleothems.

\section{Conclusions}

The use of a combination of traditional petrophysical tests and petrographical techniques together with some innovative nondestructive techniques (NDTs), such as NMR-MRI or ESEM, has been used in this research to characterize the pore system and hydric behavior of stalagmite microfabrics.

1. The combination of these techniques has been shown to be very useful, providing data interpretation for the future use of solely NDTs to select the most appropriate speleothems for paleoclimate studies.

2. This type of characterization was performed in five typical microfabrics from a calcite stalagmite and has allowed the identification of the type, shape and size of porosity and its hydric behavior. The studied microfabrics display different pore systems and hence very different hydric behaviors. Some of the studied microfabrics display primary porosity and preferential lateral permeability and preserve open porosity related to primary textures. Other microfabrics display some diagenetic signs, such as minor corrosion, vertical enhanced porosity, dissolution, and possible necking-down or occlusion of previous pores.

3. The hiatus generates a partition inside the speleothem, resulting in two different hydric subsystems, which are almost totally isolated from each other.

4. Diagenesis in sample 4, when present, appears to be restricted, in most cases, to the enlargement and connection of previous pores, while the calcite located away from pores largely preserves the primary fabrics.

5. The potential interaction between the speleothem calcite and water is higher than expected. This strongly suggests that samples should be completely dried in a desiccator before use in paleoclimate studies.

6. The NMR-MRI techniques have shown to be very useful. When applied to saturated samples, they allow the non-destructive characterization of the internal structure of the samples. When applied to dried samples, they have proven to be perfect techniques for locating and quantifying the amount of water trapped as fluid inclusions, allowing an estimation of recovery and the improvement of different methods of extraction and analysis. Therefore, a combination of NMR-MRI before and after saturation under vacuum is strongly recommended. The use of these techniques has revealed that macroscopic fluid inclusions might be more common than previously thought.

7. Finally, the petrographical and petrophysical studies are complementary and can be very useful to understanding the microstructure of different speleothem microfabrics and to confirming their suitability for use in paleoclimate reconstructions.

\section{Acknowledgments}

The study was funded by Projects CGL2007-60618-BTE, CGL201021499-BTE, GEOMATERIALES (S2009/MAT-1629), CONSOLIDERTCP (CSD2007-0058), and by the Research Groups of Paleoclimatology and Global Change (UCM-CM-910198) and Alteración y Conservación de Materiales Pétreos del Patrimonio (UCM-CM-921349). Thanks are extended to CEI-Moncloa. A JAE-Doc CSIC contract supported P. López-Arce to develop this work. We are grateful for the use of the facilities and permissions given by the Junta de Castilla y León (Spain) to access and work at the Atapuerca archeological site. The authors especially thank Ana Isabel Ortega (CENIEH) and Miguel Ángel Martín-Merino (Grupo Espeleológico Edelweiss, Burgos) for their inestimable help during cave work; to Laura González-Acebrón (CSIC-UCM) for fluid inclusion descriptions with the petrographic microscope; and to Luis Tormo, Marta Furió and Alberto Jorge García (Museo Nacional de Ciencias Naturales, CSIC - Madrid) for providing the ESEM photographs and EDS analyses. Thanks are extended to David Freire, Iván Serrano, Blanca López Gallardo, Javier Rodríguez and Javier Pérez from the Instituto de Geociencias (CSIC-UCM) and Gilberto Herrero (Dpto. Estratigrafia, UCM) for their laboratory work, suggestions, ideas, and support. The manuscript notably benefited from comments and suggestions by Dr. B. Jones and an anonymous referee.

\section{References}

Alesiani, M., Capuani, S., Maraviglia, B., 2003a. NMR study on the early stages of hydration of a porous carbonate stone. Magnetic Resonance Imaging 21 (4), 333-335.

Alesiani, M., Capuani, S., Maraviglia, B., 2003b. NMR applications to low porosity carbonate stones. Magnetic Resonance Imaging 21 (7), 799-804.

Baker, A, Smart, P.L., Edwards, R.L., Richards, D.A, 1993. Annual growth banding in a cave stalagmite. Nature 364, 518-520.

Benavente, D., Lock, P., García del Cura, M.A., Ordóñez, S., 2002. Predicting the capillary imbibition of porous rocks from microstructure. Transport in porous media 49 (1), 59-76.

Benavente, D., Cueto, N., Martínez-Martínez, J., García del Cura, M.A., Cañaveras, J.C., 2007. The role of petrophysical properties of porous building rocks on salt weathering. Environmental Geology 52, 197-206.

Borgia, G.C., Bortolotti, V., Fantazzini, P., 2001. Changes of the local pore space structure quantified in heterogeneous porous media by $1 \mathrm{H}$ magnetic resonance relaxation tomography. Journal of Applied Physics 90 (3), 1155-1163.

Borsato, A., Quinif, Y., Bini, A., Dublyansky, Y., 2003. Open-system alpine speleothems: implications for U-series dating and paleoclimate. Studi Trent. Sci. Nat., Acta Geol $80,71-83$.

Dennis, P.F., Rowe, P.J., Atkinson, T.C., 2001. The recovery and isotopic measurement of water from fluid inclusions in speleothems. Geochimica et Cosmochimica Acta 65 (6), 871-884.

Fleitmann, D., Burns, S.J., Neff, U., Mangini, A., Matter, A., 2003. Changing moisture sources over the last 330,000 years in Northern Oman from fluid-inclusion evidence in speleothems. Quaternary Research 60, 223-232.

Frappier, A.B., 2008. A stepwise screening system to select storm-sensitive stalagmites: taking a targeted approach to speleothem sampling methodology. Quaternary International 187 (1), 25-39.

Frisia, S., 1996. Petrographic evidences of diagenesis in speleothems: some examples. Spéléochronos 7, 21-30.

Frisia, S., Borsato, A., 2010. Karst. In: Alonso-Zarza, A.M., Tanner, L.H. (Eds.), Developments in sedimentology. : Carbonates in Continental Settings, 61. Elsevier, pp. 269-318.

Frisia, S., Borsato, A. Fairchild, I.J., McDermott, F., 2000. Calcite fabrics, growth mechanisms, and environments of formation in speleothems from the Italian Alps and southwestern Ireland. Journal of Sedimentary Research 70 (5), 1183-1196.

Frisia, S., Borsato, A., Fairchild, I.J., Selmo, E.M., 2002. Aragonite to calcite transformation in speleothems (Grotte de Clamouse, France): environment, fabrics and carbonate geochemistry. Journal of Sedimentary Research 72 (5), 687-699.

Genty, D., Plagnes, V., Ccausse, C., Cattani, O., Stievenard, M., Falourd, S., Blamart, D., Ouahdi, R., van-Exter, S., 2002. Fossil water in large stalagmite voids as a tool for paleoprecipitation stable composition reconstitution and paleotemperature calculation. Chemical Geology 184, 83-95.

Goldstein, R.H., 1993. Fluid inclusions as microfabrics: a petrographic method to determine diagenetic history. In: Rezak, R., Lavoi, D. (Eds.), Carbonate Microfabrics. Springer-Verlag, Berlin, pp. 279-290.

Harmon, R.S., Schwarcs, H.P., O'Neil, J., 1979. D/H ratios in speleothem fluid inclusions: a guide to variations in the isotopic composition of meteoric precipitation? Earth and Planetary Science Letters 42, 254-266.

Kendall, A.C., Broughton, P.L., 1978. Origin of fabrics in speleothems composed of columnar calcite crystals. Journal of Sedimentary Petrology 48, 519-538.

Latour, L.L, Kleinberg, R.L., Mitra, P.P., Sotak, C.H., 1995. Pore-size distributions and tortuosity in heterogeneous porous media. Journal of Magnetic Resonance Series A112, 83-91. 
Martín-Chivelet, J., Muñoz-García, M.B., Domínguez-Villar, D., Turrero, M.J., Ortega, A.I., 2006. Comparative analysis of stalagmites from two caves of northern Spain. Implications for Holocene paleoclimate studies. Geologica Belgica 9 (3-4), 323-335.

Martín-Chivelet, J., Muñoz-García, M.B., Edwards, R.L., Turrero, M.J., Ortega, A.I., 2011. Land surface temperature changes in Northern Iberia since $4000 \mathrm{yr} \mathrm{BP}$, based on $613 \mathrm{C}$ of speleothems. Global and Planetary Change 77, 1-12.

Martín-García, R., Alonso-Zarza, A.M., Martín-Pérez, A., 2009. Loss of primary texture and geochemical signatures in speleothems due to diagenesis: evidences from Castañar Cave, Spain. Sedimentary Geology 221, 141-149.

Martín-García, R., Martín-Pérez, A., Alonso-Zarza, A.M., 2011. Weathering of host rock and corrosion over speleothems in Castañar cave, Spain: an example of a complex meteoric environment. Carbonates and Evaporites 26 (1), 83-94.

Matthews, A., Ayalon, A., Bar-Matthews, M., 2000. D/H ratios of fluid inclusions of Soreq Cave (Israel) speleothems as a guide to the Eastern Mediterranean Meteoric Line relationships in the last $120 \mathrm{ky}$. Chemical Geology 166, 183-191.

McDermott, F., Frisia, S., Yiming, H., Longinelli, A., Spiro, B., Heaton, T.H.E., Hawkesworth, C.J., Borsato, A., Keppens, E., Fairchild, I.J., van der Borg, K., Verheyden, S., Selmo, E., 1999. Holocene climate variability in Europe: evidence from $\delta^{18} \mathrm{O}$, textural and extension-rate variations in three speleothems. Quaternary Science Reviews 18, 1021-1038.

McGarry, S., Bar-Matthews, M., Matthews, A., Vaks, A., Schilman, B., Ayalon, A., 2004 Constraints on hydrological and paleotemperature variations in the Eastern Mediterranean region in the last $140 \mathrm{ka}$ given by the $6 \mathrm{D}$ values of speleothem fluid inclusions. Quaternary Science Reviews 23, 919-934.

Muñoz-García, M.B., Martín-Chivelet, J., Rossi, C., Ford, D.C., Schwarcz, H.P., 2007. Chronology of Termination II and the Last Interglacial Period in North Spain based on stable isotope records of stalagmites from Cueva del Cobre (Palencia). Journal of Iberian Geology 33 (1), 17-30.

NORMAL 11/85, 1985. Assorbimento d'acqua per capillarità. Coefficiente di assorbimento capillare, CNR-ICR, Roma, Italia.

Ortega, A.I., 2009. Evolución geomorfológica del Karst de la Sierra de Atapuerca (Burgos) y su relación con los yacimientos pleistocenos que contiene. PhD Thesis, Universidad de Burgos, Spain.
Proctor, C., Baker, A., Barnes, W.L., Gilmour, M.A., 2000. A thousand year speleothem proxy record of North Atlantic climate from Scotland. Climate Dynamics 16, $815-820$.

Railsback, L.B., Sheen, S.-W., Rafter, M.A., Brook, G.A., Kelloes, C., 1997. Diagenetic replacement of aragonite by aragonite in speleothems: criteria for its recognition from Botswana and Madagascar. Spéléochronos 8, 3-11.

Railsback, L.B., Dabous, A.A., Osmond, J.K., Fleisher, C.J., 2002. Petrographic and geochemical screening of speleothems for U-series dating: an example from recrystallized speleothems from Wadi Sannur Cavern, Egypt. Journal of Cave and Karst Studies 64, 108-116.

Railsback, L.B., Liang, F., Vidal Romaní, J.R., Grandal-d'Anglade, A., Vaqueiro Rodríguez, M., Santos Fidalgo, L, Fernández Mosquera, D., Cheng, H., Edwards, R.L., 2011. Petrographic and isotopic evidence for Holocene long-term climate change and shorter-term environmental shifts from a stalagmite from the Serra do Courel of northwestern Spain, and implications for climatic history across Europe and the Mediterranean. Palaeogeography, Palaeoclimatology, Palaeoecology 305, 172-184.

UNE-EN 1936, 2007. Natural Stone Test Methods. Determination of Real Density and Apparent Density, and of Total and Open Porosity.

Viola, R., Tucci, A., Timellini, G., Fantazzini, P., 2006. NMR techniques: a non-destructive analysis to follow microstructural changes induced in ceramics. Journal of the European Ceramic Society 26, 3343-3349.

Vonhof, H.B., van Breukelen, M.R., Postma, O., Rowe, P.J., Atkinson, T.C., Kroon, D., 2006. A continuous-flow crushing device for on-line $\delta^{2} \mathrm{H}$ analysis of fluid inclusion water in speleothems. Rapid Communications in Mass Spectrometry 20, 2553-2558.

Whitehead, N.E., Ditchburn, R.G., Williams, P.W., McCabe, W.J., 1999. 231Pa and 230Th contamination at zero age: a possible limitation on U/Th series dating of speleothem material. Chemical Geology 156, 359-366.

Zimmerman, R.W., Bodvarsson, G., 1991. A simple approximate solution for horizontal infiltration in a Brooks-Corey medium. Transport in Porous Media 6, 195-205. 